\title{
Estimation of cool summer damage in the Tohoku region based on the MRI AGCM
}

\author{
Eiji KANDA $*, \dagger$, Hiromitsu KANNO **, Sayuri OKUBO **, Teruhisa SHIMADA ***, \\ Ryuhei YOSHIDA***, Takashi KOBAYASHI $* * * *$ and Toshiki IWASAKI *** \\ * NARO Agricultural Research Center, Tsukuba, Ibaragi, 305-8666, Japan \\ ** NARO Tohoku Agricultural Research Center, Morioka, Iwate, 020-0198, Japan \\ *** Graduate School of Science, Tohoku University, Sendai, Miyagi, 980-8579, Japan \\ **** Faculty of Agriculture, Yamagata University, Tsuruoka, Yamagata, 997-8555, Japan
}

\begin{abstract}
We analyzed the impact of climate change due to global warming on the risk of cool summer damage to paddy rice in the Tohoku region of Japan. We downscaled the atmospheric general circulation model of the Meteorological Research Institute (MRI AGCM) to $10 \mathrm{~km}$, and we used monthly average temperatures and their standard deviations to correct the bias of the simulated temperatures. We did not use daily averaged temperatures to determine the risk of cool summer damage. Instead, we used the cooling degree calculated from the average daily temperature over a period of time (CDAT). We also used the standardized yield calculated from temperatures during the month preceding heading. An examination of the reproducibility of cooling damage occurring under the current climate was based on bias-corrected data which revealed that although the simulated risk of cool summer damage slightly underestimated both the CDAT and the standardized yield, the areal distributions of risk were similar to those in years of cool summer damage. We assumed that the heading stage occurred 15.6 days earlier than current climate because of the impact of temperature increase under the future climate and therefore calculated the CDAT and standardized yield by advancing the critical period by half a month. During the second- and third-coolest summers under the future climate scenario, the risk of cool summer damage decreased in the southern Tohoku region facing the Pacific Ocean and in Aomori Prefecture on the Japan Sea side, but the risk of cool summer damage was almost the same as during the observed cool summer of 1980. In summary, our results revealed that under a future climate, simulated by the MRI AGCM, the risk of cool summer damage will persist in the Tohoku region; risk management for cool summer damage will therefore be essential, even though global temperatures rise.
\end{abstract}

Key words: Cooling degree by average temperature, Cool summer damage, Global warming, MRI AGCM, Standardized yield.

\section{Introduction}

The various impacts of climate change on human activities and agriculture due to global warming are a

Received; March 18, 2014.

Accepted; July 9, 2014.

${ }^{\dagger}$ Corresponding Author: kanda@agri.kagoshima-u.ac.jp

${ }^{\dagger}$ Present Affiliation: Faculty of Agriculture, Kagoshima University

DOI: 10.2480/agrmet.D-14-00004 matter of concern. Among these impacts, the effect of climate change on paddy rice production, which accounts for one-third of global crop production, is extremely important with respect to the supply and demand of global crops. Several predictions, based on simulation models, have been made regarding paddy rice production under future global warming scenarios (Horie et al., 1995; Hayashi et al., 2001; Shimono, 2008). Most of these predictions have been based on climate scenarios in which the future temperature was assumed to be a few degrees Celsius above the average temperature of the past several decades. These predic- 
tions have not made use of Global Climate Models (GCMs). Rising temperatures in tropical and temperate areas pose risks of productivity losses due to increased damage by pests, increased precipitation, and sterility due to flowering damage caused by an early flowering season. By way of contrast, rising temperatures in regions with cold climates are expected to increase productivity because of the fertilization effect caused by rising levels of carbon dioxide and the reduced risk of low temperatures (Horie et al., 1995; Hayashi et al., 2001). However, Shimono (2008, 2011) has shown that if the current trend of increasing temperatures continues only in the spring in northern Japan, the risk of cool summer damage will increase because of the advance of warming in the spring.

The Tohoku region, which is an area with a cold climate, is a region of paddy rice production. The yield of the rice paddies in this region was $573 \mathrm{~g} \mathrm{~m}^{-2}$ in 2013 and accounted for $25 \%$ of the total area that planted in rice and $27 \%$ of the national production of rice (MAFF, 2013a). The region is also famous for the good taste of its rice. However, despite the stabilization of yield by various technical improvements, the region has been plagued by cool summer damage in recent years. During the 40 years from 1974 to 2013, cool summer damage occurred in eight of the years, including 2003. When cool summer damage occurs in the Tohoku region, cold northeasterly winds, called Yamase winds, sometimes blow across northern Japan during the Baiu season. During a typical Yamase event, the temperature in northern Japan is lower on the eastern (Pacific) side of the central mountain range than on the western (Japan Sea) side, because the westward movement of the cold air mass is blocked by the mountains (Kudoh, 1984). The persistence of the Yamase winds cools the summer climate, which reduces rice production. Moreover, the trend of increasing temperatures in the Toho$\mathrm{ku}$ region during the summer is currently not much different from the trend in other seasons (Shimono, 2011). Even in recent years, inter-annual variations of summer temperatures have resulted in sometimes hot and sometimes cool summers (Kanno, 2004).

Iizumi et al. $(2007,2011)$ have estimated that the damage to rice yields from cool summers is mitigated in northern Japan, based on a regional climate model downscaled from GCMs. However, limitations on the accuracy of GCMs confound estimates of the risk of damage to rice production in an extremely cool sum- mer. On the basis of studies with several GCMs from the Coupled Model Intercomparison Project, phase 3 (CMIP3), Endo (2012) has reported that the Yamase period will be delayed in the future and that the frequency of Yamase winds in August will increase. In addition, according to the Model for Interdisciplinary Research on Climate, version 5 (MIROC5), the latest climate scenario, the Yamase will continue to blow, and relatively cool summers will occur even in a warmer future (Kanno et al., 2013). Because these GCM-based analyses have revealed the frequency of the Yamase phenomenon and continuing cool summers there is a pressing need to use climate scenarios to evaluate the risk of cool summer damage to paddy rice in the future.

During a cool summer, the temperature is cooler on the Pacific Ocean side of the Tohoku region than on the Japan Sea side. However, both the Japan Sea and Pacific Ocean sides of the Tohoku region appear together in the GCM, because the GCM is used for global climate prediction. For example, the latest MIROC5 horizontal resolution was $\mathrm{T} 85$, which corresponds to 256 longitudinal $\times 128$ latitudinal global horizontal grids. The southwest end of the mesh that contains the Miyagi and Yamagata prefectures is at a latitude of $37.8205^{\circ} \mathrm{N}$ and a longitude of $139.9219^{\circ} \mathrm{E}$, and the northeast end is at a latitude of $39.2215^{\circ} \mathrm{N}$ and a longitude of $141.3281^{\circ} \mathrm{E}$; the size of this region is about 120 $\mathrm{km} \times 160 \mathrm{~km}$, with most parts of the Miyagi and Yamagata prefectures fitting inside. Modeled temperatures rise in the future, and temperature fluctuations are therefore projected to be identical on the Japan Sea and Pacific Ocean sides. The precision of the modeled temperatures will therefore be inadequate to simulate temperatures in the Tohoku region, where the impact of the Yamase differs greatly between the Japan Sea and Pacific Ocean sides (Hayashi et al., 2001; Yokozawa, 2003). However, the global atmospheric models developed by the Meteorological Research Institute (MRI AGCM: Mizuta et al., 2012) use ultra-highresolution grids with mesh dimensions of $20 \mathrm{~km}$.

The objective of this study was to estimate changes in the risk of cool summer damage to paddy rice in the Tohoku region under a future climate scenario. We further downscaled the MRI AGCM to a mesh dimension of $10 \mathrm{~km}$, as did Yokozawa (2003), and we performed a bias correction to make the current and future standard deviations of the model temperatures identical 
to the standard deviation of the observed temperatures.

\section{Materials and Methods}

\subsection{MRI AGCM characteristics and bias correction}

We used a regional climate model (Japan Meteorological Agency Nonhydrostatic Model; JMA-NHM) to downscale the ultra-high-resolution, global atmospheric model $(20-\mathrm{km}$ mesh, $6 \mathrm{~h})$ provided by the Meteorological Research Institute to a $10-\mathrm{km}$ mesh and 1-h time interval. The JMA-NHM is an operational nonhydrostatic model for regional, numerical weather prediction developed by the Japan Meteorological Agency. The predictions of the MRI AGCM for the future (2075-2099) are the results of experiments conducted according to the A1B scenario (the concentration of $\mathrm{CO}_{2}$ in the atmosphere near the end of the $21^{\text {st }}$ century rises to $700 \mathrm{ppm}$ ). According to the MRI AGCM, even in the future climate, Yamase-like, climate cooling events will occur in the same way as they do under current climate (1979-2003) conditions, although their strength will decrease slightly (Endo, 2012).

We used the MRI AGCM 10-km mesh model to calculate daily average temperatures for each mesh from hourly data. Hereafter, we refer to the current climate as the MRIbc and to the future climate as the MRIbf. We also calculated distance-weighted averages of the $10-\mathrm{km}$ mesh temperatures from real-time, daily average temperatures in 1-km meshes (Kanno, 1997) within each $10-\mathrm{km}$ mesh (observed value).

The MRIbc-simulated temperatures were higher than the observed values in the Tohoku region (Table 1). Examination of annual changes over 25 years, in terms of the standard deviations of the temperatures, revealed that the MRIbc-simulated standard deviations tended to decrease. For this reason, we followed Iizumi et al. (2010) by performing a bias correction of the daily average temperatures, so that the 25-year average of the MRIbc-simulated temperatures and its annual variation matched the corresponding monthly observed value and its annual variation.

It is generally assumed that the interannual variability of monthly mean air temperature is normally distributed. We first calculated the 25-year averages and the standard deviations of the monthly average temperatures for the MRIbc and MRIfc model temperatures and observed temperatures. We then calculated the probability associated with a certain daily average temperature based on the normal distribution of MRIbc temperatures. We estimated the daily temperature associated with that probability in the normal distribution of the corresponding observed temperatures for a given mesh.

The standard deviations of the 25-year average, MRIb-simulated temperatures under the current and future climate scenarios were almost identical (Table 1). For the average temperature on a certain day in the future climate, we used the monthly normal distribution of MRI future and observed values and performed a bias correction in the same way that we corrected the current climate temperatures for bias. Finally, we added the difference between the MRIbf and MRIbc of the corresponding mesh. For the actual calculation, we used the function in the programming language $\mathrm{R}$ for determining the cumulative and discrete probabilities of the normal distribution function. We denote the simulated $10-\mathrm{km}$-mesh average daily temperatures for the current climate after bias correction as MRIc; we denote the corresponding temperatures for the future climate as MRIf.

Table 1. Characteristics of current (1979-2003) and future (2075-2099) temperatures $\left({ }^{\circ} \mathrm{C}\right)$ before and after bias correction in the Tohoku region. MRIb is before bias correction, and MRI is after bias correction. Observed values are based on real-time data.

\begin{tabular}{lcccccccc}
\hline & \multicolumn{2}{c}{ Jun. } & \multicolumn{2}{c}{ Jul. } & \multicolumn{2}{c}{ Aug. } & three months AVG \\
& AVG & SD & AVG & SD & AVG & SD & AVG & SD \\
\hline MRIb current & 18.4 & 0.750 & 21.8 & 1.099 & 23.0 & 0.759 & 21.1 & 0.640 \\
MRIb future & 21.1 & 0.760 & 24.9 & 1.098 & 25.6 & 0.984 & 23.9 & 0.710 \\
MRI current & 16.5 & 0.992 & 20.1 & 1.430 & 21.8 & 1.253 & 19.5 & 0.893 \\
MRI future & 19.2 & 1.001 & 23.2 & 1.409 & 24.4 & 1.293 & 22.3 & 0.924 \\
Observed value & 16.5 & 1.051 & 20.1 & 1.435 & 21.8 & 1.331 & 19.5 & 0.852 \\
\hline
\end{tabular}




\subsection{Growth prediction}

Estimation of the rice heading stage was performed with the widely used DVI-DVR model (Horie and Nakagawa, 1990). The relevant equation is:

$$
D V R=\left(\frac{1}{G}\right)\left(\frac{1-e^{B\left(L-L_{\mathrm{c}}\right)}}{1+e^{-A\left(T-T_{\mathrm{h}}\right)}}\right)
$$

where $D V R$ is the growth rate per day, $T$ is the daily average temperature $\left({ }^{\circ} \mathrm{C}\right.$ ), and $L$ is day length (hours) . $G$ is the minimum number of days required for reaching the heading stage, $L_{\mathrm{c}}$ is the critical day length, and $T_{\mathrm{h}}$ is the temperature at which DVR is half the maximum rate at the optimum temperature. $A$ and $B$ are parameters. We determined the parameters $\left(G, T_{\mathrm{h}}, L_{\mathrm{c}}\right.$, $A$, and $B$ ) of Eq. (1) by using cultivation data for the variety "Hitomebore" from cultivation experiments in three locations, as follows: (1) the fields of the $\mathrm{Na}$ tional Agricultural Research Center for the Tohoku Region (1997-2010); (2) the coordinated experiments of the agricultural experiment stations of the Daisen campus of the National Agricultural Research Center for the Tohoku Region and Iwate, Yamagata, and Fukushima (2004-2007); and (3) the field tests of farmed fields in Hachinohe during 2010. Furthermore, from the panicle formation stage to the heading stage, we set the total effective temperature day statistic for days with daily mean temperatures above $10^{\circ} \mathrm{C}$ to $310^{\circ} \mathrm{C} \cdot$ day (Kanda et al., 2002). We assumed 20 May to be the transplanting date and used the 25 -year average temperatures of the future and current climates to calculate the heading stage. However, during the period 20-28 May, we used the 25-year averages (1979-2003) of the observed mesh temperatures for the current climate. For the future climate, we used the 25-year averages of the corresponding mesh, to which we added the value of the average temperature rise in June. In addition, we excluded from the calculation meshes locations where heading does not occur in August under current climate conditions.

\subsection{Risk assessment of cool summer damage}

In assessing the risk of cool summer damage, we used the cool-degree-days parameter (CDD) proposed by Uchijima (1976). CDD is calculated by using the daily average temperature of the days from the panicle formation stage until the heading stage, and by cumulatively adding (20-T) for each day with an average temperature below $20^{\circ} \mathrm{C}$, and $0^{\circ} \mathrm{C}$ for each day with an average temperature above $20^{\circ} \mathrm{C}$. However, because we used a climate scenario model, in addition to using the daily average temperature, we also performed calculations using the CDAT method, which employs the average temperature during a period of $n$ days, where $n$ is the number of days from the panicle formation stage until the heading stage, and AT is the average temperature during that period. The relevant statistic is $(n)$ (20-AT) ${ }^{\circ} \mathrm{C} \cdot$ day when the AT is under $20^{\circ} \mathrm{C}$, and $0^{\circ} \mathrm{C}$ -day when the AT is above $20^{\circ} \mathrm{C}$.

In addition to the CDD and CDAT, we determined the relationship between the average temperature of the month preceding heading and the standardized yield. We used that relationship to assess the risk of cool summer damage. We assigned a standardized yield of 100 to the five-year average yield, except for the lowest and highest values of the preceding seven years. We considered meshes with a yield index below 90 to be at risk of cool summer damage (MAFF, 2013b). We used yield data from the yields of municipalities surrounding Hachinohe (MAFF, 2013a) and temperature data for Hachinohe from the Automated Meteorological Data Acquisition System (AMeDAS). For these data, we used the general additive model in $\mathrm{R}$ and used a cubic spline interpolation method to smooth the relationship between temperature and standardized yield (Takezawa, 2007).

\section{Results}

\subsection{MRI AGCM bias correction}

Examination of the MRIbc-simulated, 25-year average of daily average temperatures under the current climate scenario revealed that the average MRIbc temperature in the Tohoku region for three months from June to August was $21.1^{\circ} \mathrm{C}$, whereas the three-month average of the observed values was $19.5^{\circ} \mathrm{C}$. The MRIbc-simulated temperature was therefore higher than the observed value by $1.6^{\circ} \mathrm{C}$ in the Tohoku region (Table 1). In the area around the city of Hachinohe, the analogous temperature difference was $2.5^{\circ} \mathrm{C}$ during the same three-month period.

An accurate projection of temperatures is extremely important for evaluating the risk of cool summer damage in the Tohoku region in the future. Cool summer damage occurs when summer temperatures tend to be lower than temperatures during normal years (average values of the past 30 years).

Figure 1 presents the probability densities of the normally distributed annual variations of the MRIbc- 
(a)

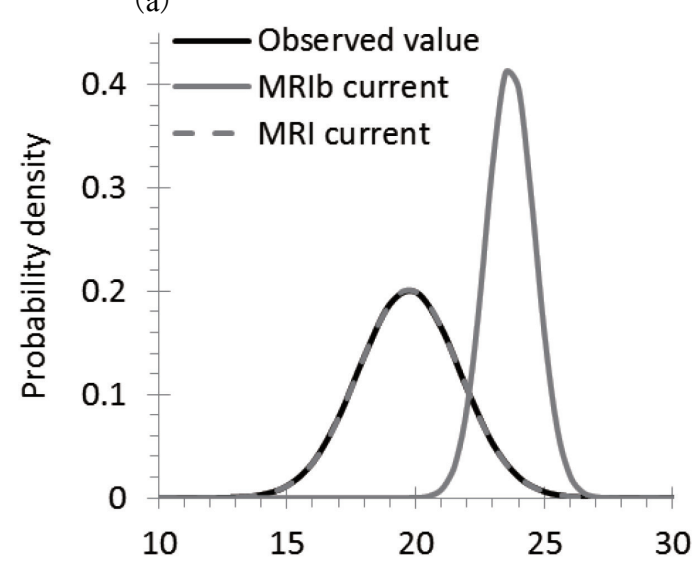

Monthly average temperature $\left({ }^{\circ} \mathrm{C}\right)$ (b)

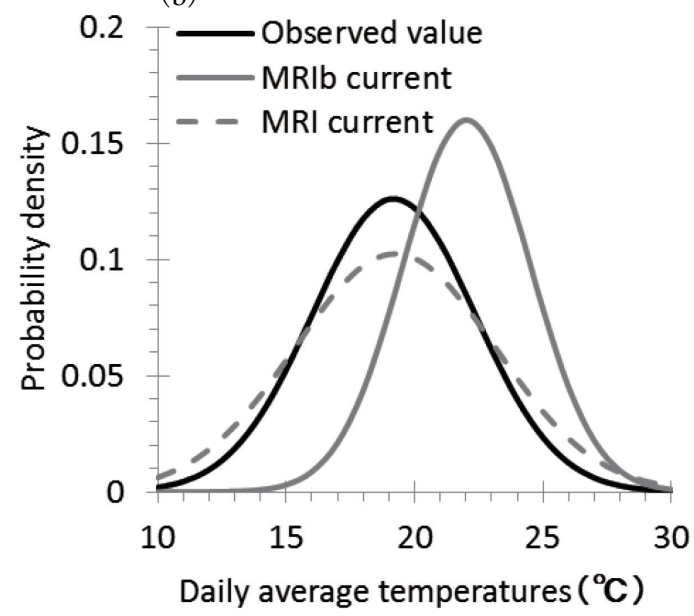

Fig. 1. Differences in probability density distributions of observed values of temperature and temperatures before and after bias correction in the mesh around Hachinohe. a) Monthly average temperatures in July. b) Daily average temperatures on 16 July.

simulated and MRIc-simulated monthly average temperatures for the current climate and the corresponding probability densities of the observed values in the mesh around Hachinohe (central coordinates: lat $40.458^{\circ} \mathrm{N}$, long $141.482^{\circ} \mathrm{E}$ ). Although the distributions of monthly average temperatures for the MRIbc-simulated and observed temperatures differed, after bias correction, the MRIc-simulated and observed values matched perfectly (Fig. 1a). However, because daily temperature variations and annual fluctuations differed between the MRIc-simulated and observed values, the probability density distributions of the daily average temperatures did not match (Fig. 1b). Although the standard deviations of the simulated average temperatures for all meshes in the Tohoku region did not perfectly match the standard deviation of the observed temperatures, the correspondence was clearly better for the MRIc than for the MRIbc (Table 1).

The temperature rises estimated from the differences between the MRIf and MRIc averaged $2.9{ }^{\circ} \mathrm{C}$ and $2.8^{\circ} \mathrm{C}$ for Hachinohe and the Tohoku region, respectively (Fig. 2). The temperature rise was far greater in meshes on the Pacific Ocean side and in high-latitude regions centered on the Shimokita Peninsula. To examine the seasonal pattern of the temperatures, we smoothed the 25-year averages of the daily average temperatures for MRIc and MRIf by calculating sevenday moving averages three times. The obtained values

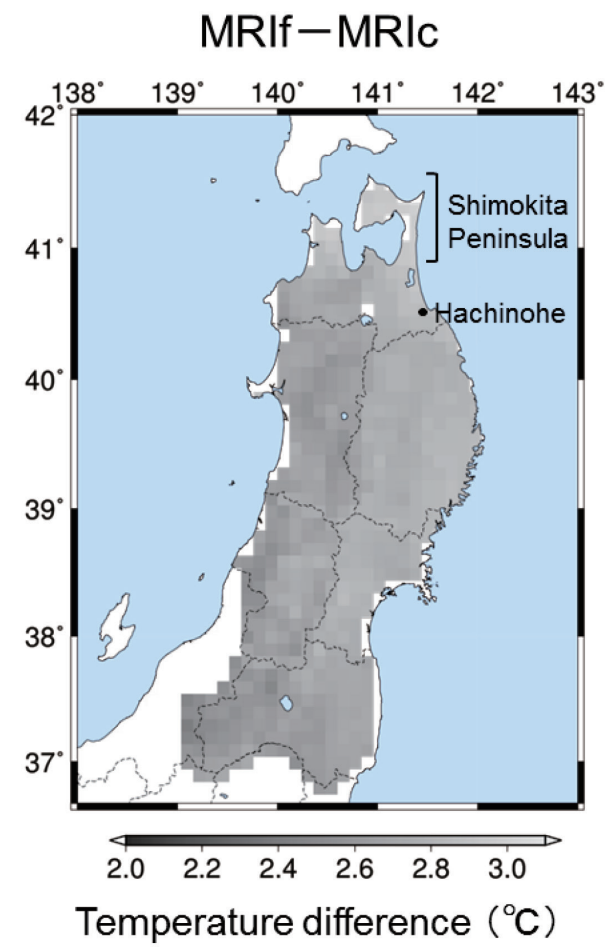

Fig. 2. Distribution of temperature differences between the future climate (2075-2099) and the current climate (1979-2003) throughout the Tohoku region. 


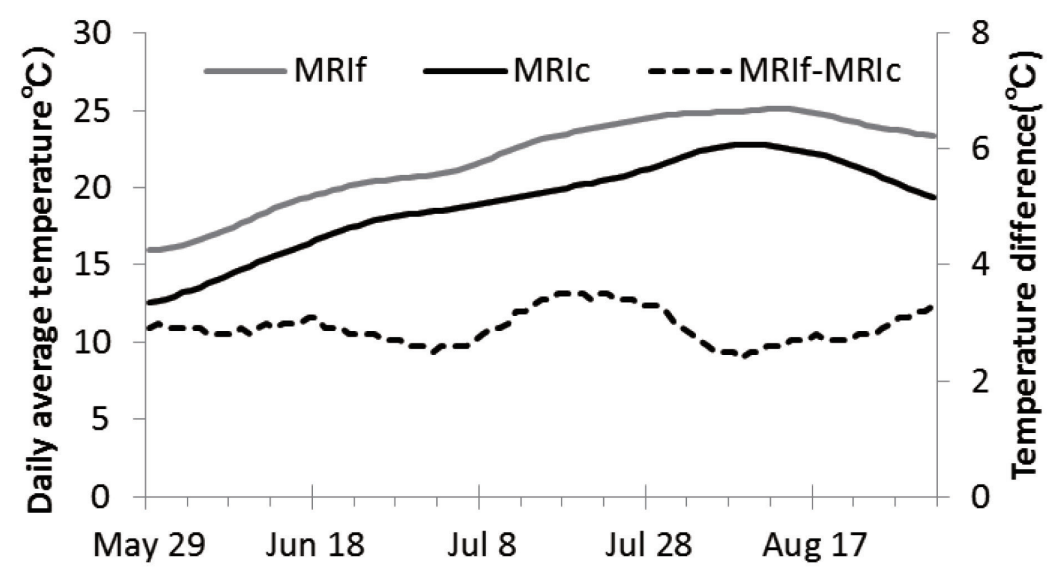

Fig. 3. Variation of simulated temperatures with day of the year for the current climate and the future climate. The lines represent 25 -year averages. Numbers on the abscissa are month and day of the month.

for MRIc and MRIf followed nearly identical patterns throughout the data period (Fig. 3).

\subsection{Reproduction of the risk of cool summer dam-} age under the current climate

The current heading stage of paddy rice in the Tohoku region occurs mainly during the 1-10 August period. However, as growth tends to be delayed during cool summer years, we assumed the heading stage to be during 6-15 August. As the reference for the standardized yield, we fixed the period from 16 July to 15 August to be the month preceding heading. Figure 4 shows the relationship between the average temperature during the month preceding heading and the standardized yield. The outlier datum came from 1981, when the major factors that impacted production were the adverse effects of Typhoon 15 and the poor rooting and growth delay caused by the low temperatures after planting.

To determine the dependence of the amount of cooling on the method of calculation, we compared the CDD and CDAT determined from the observed values under the current climate. There was little difference in

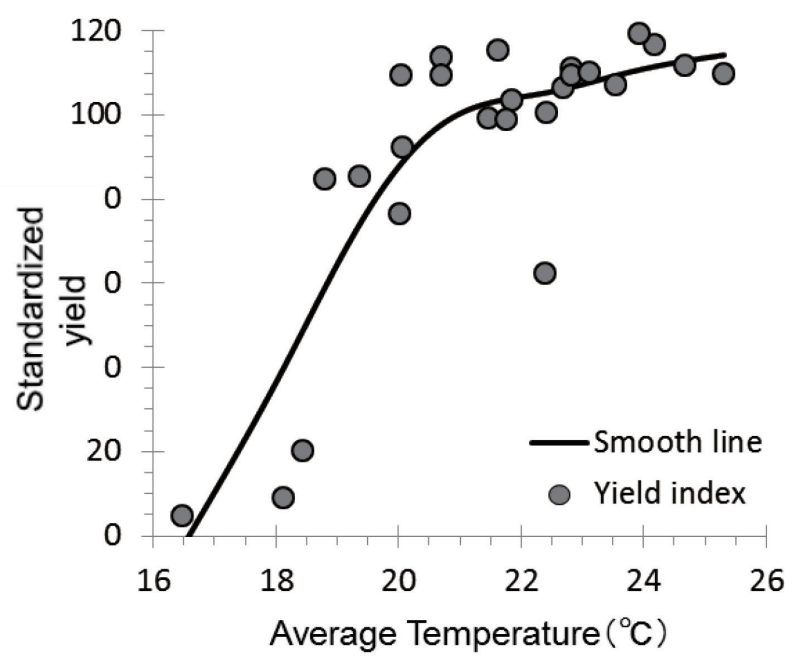

Fig. 4. Standardized yield versus average temperature from 16 July to 15 August. The smooth line was determined by the general additive model. 
a) $\mathrm{CDD}$ in 1980

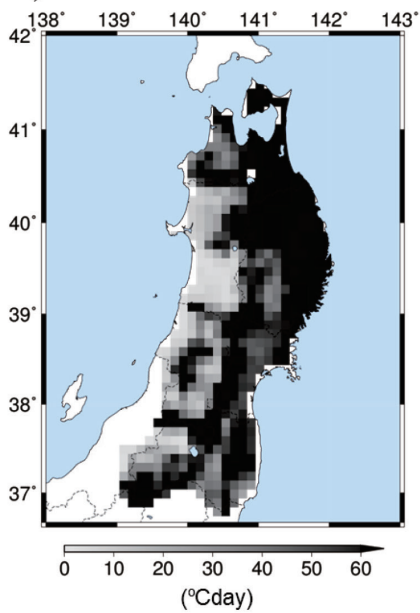

b) CDAT in 1980

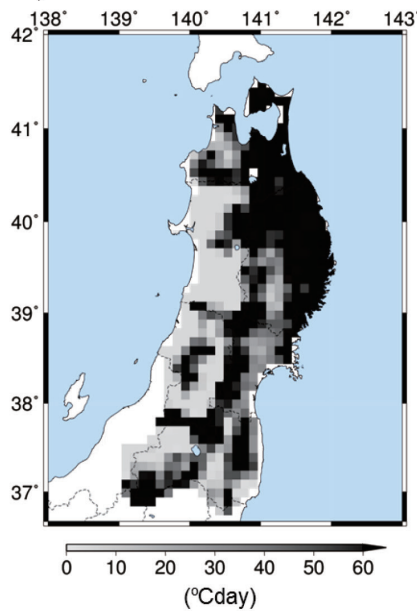

c) CDAT in second-coolest summer by MRIc

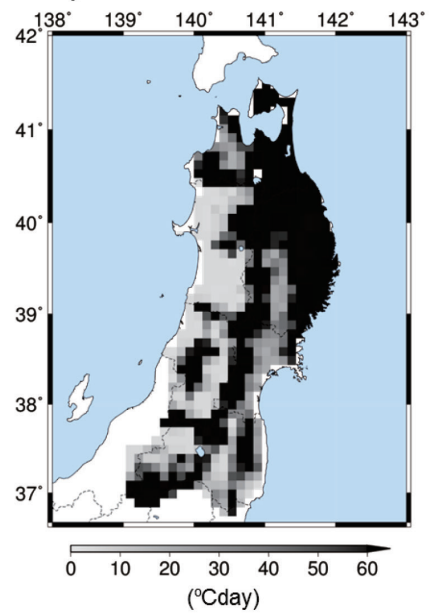

Fig. 5. Comparison of distributions of the amount of cooling quantified by a) cooling degree-days (CDD) during the $1980 \mathrm{cool}$ summer, b) the cooling degree calculated from actual average temperature (CDAT) during the 1980 cool summer, and c) CDAT according to MRIc during the second-coolest summer.
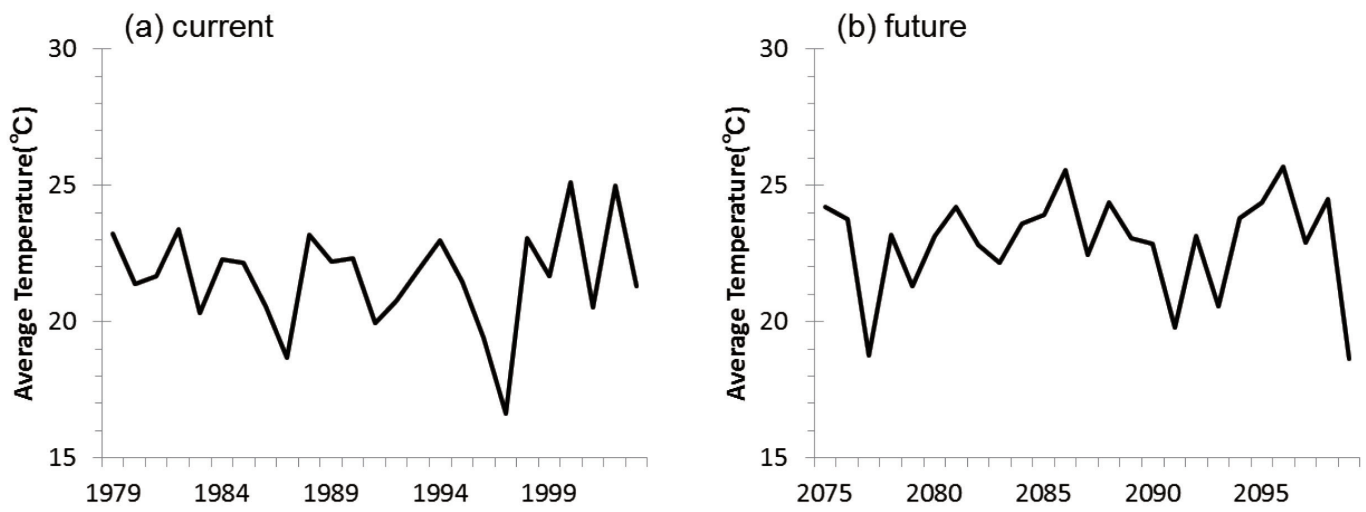

Fig. 6. Time series of the average temperature during the critical period for cool summer damage in the mesh around Hachinohe. a) Average temperatures from 16 July to 15 August. b) Average temperatures from 1 to 31 July.

the distributions for areas where the amount of cooling was above $60^{\circ} \mathrm{C} \cdot$ day, but the area in which the CDAT ranged from $10^{\circ} \mathrm{C} \cdot$ day to $60^{\circ} \mathrm{C} \cdot$ day was smaller for the CDD (Fig. 5). Figure 5 shows the amount of cooling during the second-coolest summer (1980), according to the observed values, because during the coolest summer (1993), the area where the amount of cooling was above $60^{\circ} \mathrm{C} \cdot$ day was so wide, that no differences between methods of calculation could be distinguished.

Next, to assess the validity of the bias correction, we used MRIc and observed values to compare the CDAT values for three years with cool summers. Figure 6a shows the time series of the average temperatures during a critical period for cool summer damage at Hachinohe (from 16 July to 15 August). However, because the GCM predicts climate change rather than year-toyear variations, we equated the coolest, second-coolest, and third-coolest summers to the summers associated with the lowest to the highest temperatures during the critical period for Hachinohe. For the observed values, meshes at risk of cool summer damage with a CDAT above $20^{\circ} \mathrm{C}$ - day represented $80.7 \%$ of all meshes of the Tohoku region in $1993,65.5 \%$ in 1980 , and $52.2 \%$ in 2003. For the MRIc, the analogous meshes represented 
a) 1980 second-coolest summer by observed data

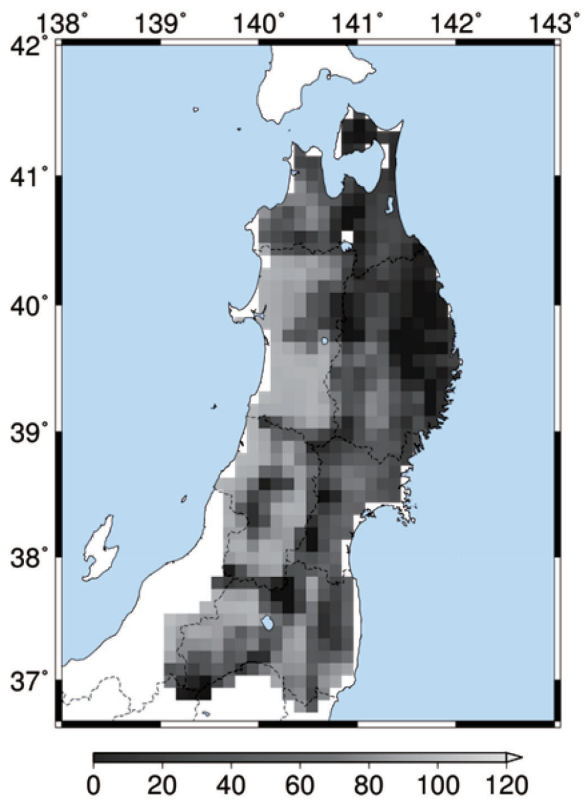

b) second-coolest summer by MRIc

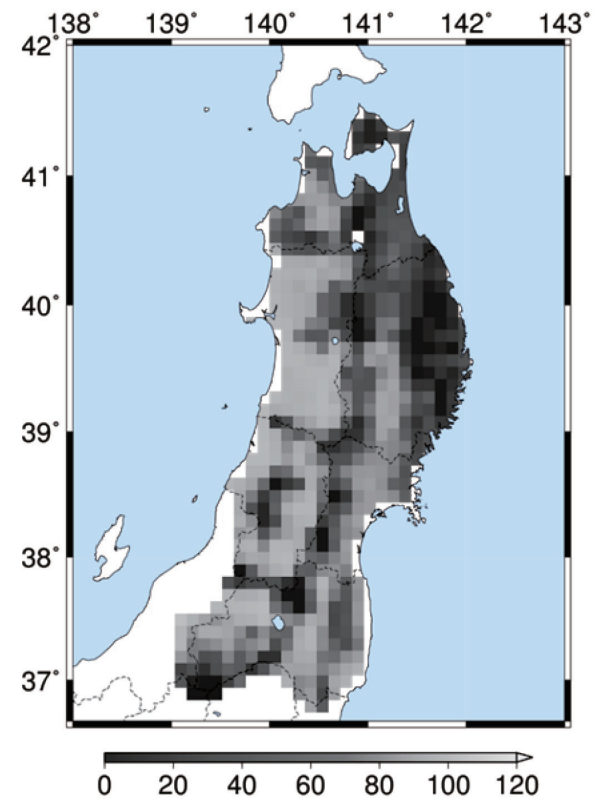

Fig. 7. Comparison of standardized yield distributions a) during the 1980 cool summer and b) during the second-coolest summer according to the MRIc.

$70 \%$ in the coolest summer, $65 \%$ in the second-coolest summer, and $38.1 \%$ in the third-coolest summer. These percentages were slightly lower than the percentages estimated with the observed values. However, areas with large CDATs were almost identical for the MRIc and observed values. They were centered on the Pacific Ocean side, on the Japan Sea side of the Aomori Prefecture, and in the mountains on the Japan Sea side (Fig. 5) . Examination of standardized yields revealed that meshes with values below 90, which could be determined to be those with cool summer damage, represented $96.6 \%$ of all meshes of the Tohoku region in $1993,76.4 \%$ in 1980 , and $66.1 \%$ in 2003 based on observed values. Based on the MRIc, these percentages were marginally lower than on observed values: $79.7 \%$ in the coolest summer, $67.7 \%$ in the second-coolest summer, and $45.7 \%$ in the third-coolest summer (Fig. 7). The distributions of meshes with low yield indices were similar for the MRIc and observed temperatures.

\subsection{Future risk of cool summer damage}

Because the critical period for cool summer damage depends on the heading stage of paddy rice, we esti- mated the disparity of the heading stages of paddy rice under current and future climates. We considered the heading date of "Hitomebore", which is cultivated mainly in the Tohoku region, and estimated that heading would occur an average of 15.6 days earlier for the whole of Tohoku (Fig. 8). For this reason, we set the heading period for calculating the CDD to 21-31 July and the advanced the period for obtaining the yield and standardized yield to 1-31 July. Figure $6 \mathrm{~b}$ shows the temperatures during the critical period for Hachinohe (1-31 July). The lowest, second-lowest, and thirdlowest temperatures occurred in 2091, 2077, and 2099, respectively. However, because GCMs are not yearly forecast models, we labeled these years as the first-, second-, and third-coolest summers.

When we considered the CDAT under the future climate for Hachinohe in the year with the lowest average temperature in July, we found that $52.8 \%$ of the meshes were at risk of cool summer damage. These meshes had a high CDAT above $20^{\circ} \mathrm{C} \cdot$ day. However, the risk of cool summer damage was low during the second- and third-coolest summers, the corresponding 


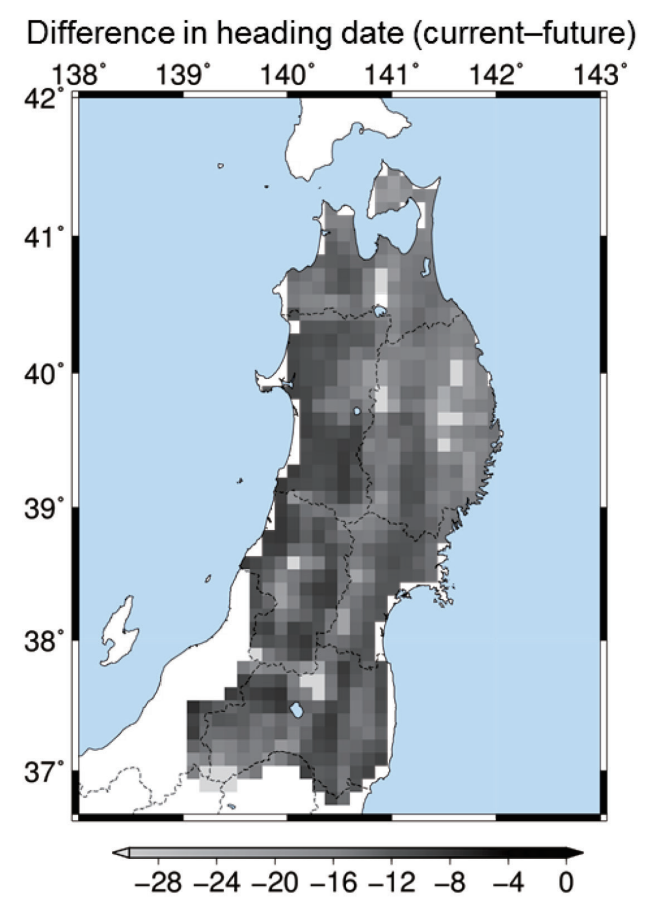

Number of days difference

Fig. 8. Distribution of the difference in estimated heading dates between the current climate and the future climate. The difference (current - future) is the number of days between the estimated heading dates.

proportions being $15.2 \%$ and $19.3 \%$, respectively.

Examination of the distribution of CDD during the coolest summer revealed that the CDAT exceeded $20^{\circ} \mathrm{C} \cdot$ day for the Pacific coast of the Aomori Prefecture, the Iwate Prefecture coast, the northern coast of the Miyagi Prefecture, the coast of the Fukushima Prefecture, and the mountainous areas on the Pacific side; whereas, it was below $10^{\circ} \mathrm{C} \cdot$ day for the inland areas of the Iwate Prefecture and the northern inland areas of the Miyagi Prefecture (Fig. 9a). However, the possibility of cool summer damage was apparent, because the $\mathrm{CDD}$ was over $40^{\circ} \mathrm{C} \cdot$ day in the same areas.

Examination of the standardized yield distribution during the coldest year revealed that $67.4 \%$ of the meshes had a standardized yield below 90. Meshes centered on the Pacific Ocean side of the Tohoku region were determined to be at risk of cool summer damage comparable to the damage that occurred in 2003. However, the standardized yield for the Aomori
Prefecture on the Japan Sea side did not decrease substantially (Fig. 9b). During the second- and thirdcoolest summers, only $36.5 \%$ and $25.4 \%$, respectively, of the meshes were determined to be at risk of coolsummer damage. With the exception of the Pacific coast of the Aomori Prefecture and the coast of the Iwate Prefecture, the standardized yield did not decrease.

The CDD and the standardized yield both showed that during the second- and third-coolest summers of the future climate, the risk of cool summer damage was low in the southern part of the Tohoku region facing the Pacific Ocean and in the Aomori Prefecture on the side by the Japan Sea. Also apparent was the possibility that the frequency and extent of cool summer damage would decrease because of the increase of temperature. However, the coolest summer of the future climate presented almost the same risk of cool summer damage as the second-coolest summer of the current climate, i.e., the cool summer of 1980 (Figs. 5, 7, and 9).

\section{Discussion}

\subsection{Future temperature variation}

A cool summer seriously damages rice production on the Pacific Ocean side of the Tohoku region under the present climate (Iizumi et al., 2011). When cool summer damage occurs in the Tohoku region, Yamase winds-cold northeasterly winds-sometimes blow across northern Japan. The Yamase will continue to blow, and relatively cool summers will occur, even if future years are predicted to increase in temperature (Endo 2012; Kanno et al. 2013). Examination of the areal distribution of increases of temperature, which is determined by the MRIc and MRIf models, revealed that the temperature increases were far higher in high-latitude areas and along the Pacific coast (Fig. 2), the suggestion being that a spatial resolution finer than $10 \mathrm{~km}$ is necessary to assess the risk of cool summer damage in the Tohoku region.

Predicting climate change includes various uncertainties in the modeling process. Therefore, limitations of the accuracy of GCMs confound estimating extreme years and inter-annual variability (Iizumi et al., 2007) . An extremely cool summer seriously damages rice production under the current climate. The standard deviations of the 25-year monthly average of MRIb temperatures were smaller than the observed tempera- 
a) CDAT

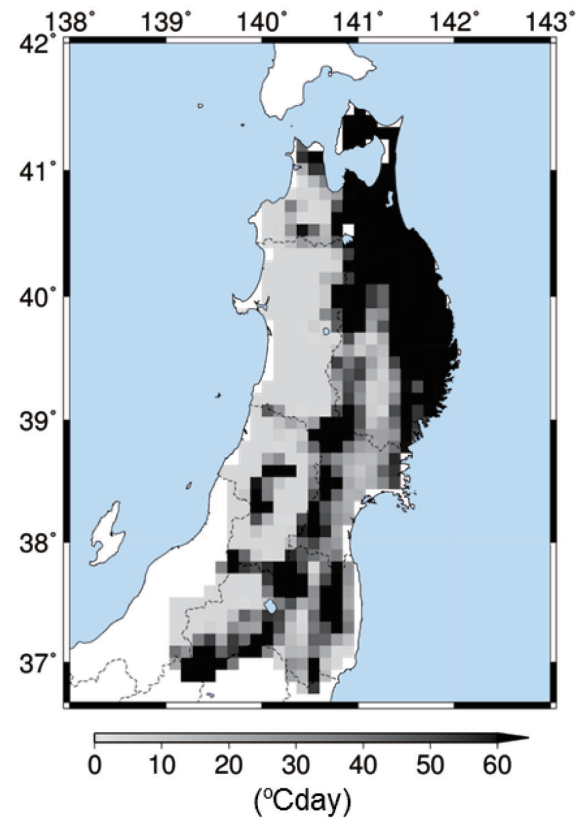

b) Standardized yield

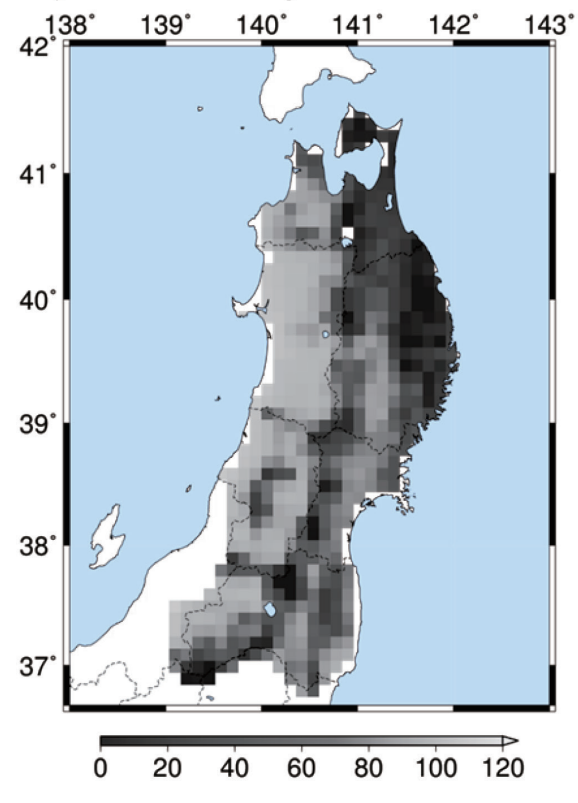

Fig. 9. Distributions of a) the extent of cooling based on average temperature (CDAT) and b) the standardized yield of the coolest summer in the future climate.

tures (Fig. 1). Bias refers to the difference between the simulated values and observations and is the most serious factor responsible for decreasing the reliability of risk predictions. We used the standard deviations of the 25-year monthly averages to reduce the interannual variability of monthly temperatures in the GCM bias. The areas with high risk of cool summer damage were identical, and the years with unusually low temperatures could be reproduced with bias correction (Figs. 5 and 7). Thus, assuming the annual variations of temperature to be normally distributed and applying a bias correction based on the monthly average and standard deviation of temperature appears to be an appropriate method for assessing the risk of cool summer damage.

\subsection{Future risk of cool summer damage}

Because using daily values is not recommended in GCMs, analytical limitations require the use of values averaged over a fixed period of time (Hayashi et al., 2001). However, when assessing damage due to cold weather, care is necessary when using the average temperature for a period to assess the risk of cool summer damage, because irreversible damages can be caused by temporarily low temperatures, even if the average temperature during the critical period is high
(Hayase et al., 1969; Satake, 1976). In the present study, because we used a CDD calculated from the average temperature during a time interval, there was a tendency to underestimate the risk of cool summer damage. We therefore assessed the risk of cool summer damage comprehensively by using the standardized yield calculated from the average temperature during the month before heading, which is influenced less than the CDD by temperature variations. Even in the future climate, the risk of cool summer damage remained centered around the Pacific Ocean side of the Tohoku region (Figs. 5, 7, and 9). The demonstration that the risk of cool summer damage remains, even when using a GCM that predicts a temperature increase, is important when considering how to stabilize the production of paddy rice in northern areas of Japan in the future. Further studies that also focus on the differences of summer temperature variations due to GCM differences are anticipated.

Assessment of the risk of cool summer damage requires consideration of the effect of an increase of atmospheric carbon dioxide on cold resistance in addition to the impact of low temperatures during the critical period. Because an increase of carbon dioxide con- 
centration has been reported to weaken cold resistance and exacerbate cool summer damage (Okada et al., 2005; Shimono et al., 2008), the risk of cool summer damage in the future climate will likely be even higher. By way of contrast, because high water temperatures before panicle formation have been shown to increase cold resistance (Shimono et al., 2007), an increase in the air temperature during this period is expected to raise the water temperature and reduce the risk of cool summer damage. Furthermore, because the risk of cool summer damage also depends on the cropping season and variety selection, a comprehensive study that also includes the avoidance of high temperature stress and the effects of low temperature on ripening conditions is necessary.

In summary, even in future climates projected using GCMs, in which uncertainty is unavoidable, the risk of cool summer damage in the Tohoku region will persist. To stabilize production during global warming, it will be essential to not only develop cultivation methods adapted to temperature increases and select heattolerant varieties but also to establish risk management methods to minimize cool summer damage. In particular, the development of a cultivation management system that supports the reduction of weather hazard risks by using long-term forecasts to deal with climate change will likely be necessary.

\section{Acknowledgments}

This research was partly supported by a MAFF (Ministry of Agriculture, Forestry and Fisheries, Japan) project, "Development of Mitigation and Adaptation Techniques for Global Warming in the Sectors of Agriculture, Forestry and Fisheries," and MEXT (Ministry of Education, Culture, Sports, Science and Technology, Japan) project, "Research Program on Climate Change Adaptation (RECCA)." The downscaling was performed using the supercomputer system SX-9 of the Cyberscience Center, Tohoku University.

\section{References}

Endo, H., 2012: Future changes of Yamase bringing unusually cool summers over northeastern Japan in CMIP3 multi-models. Journal of the Meteorological Society of Japan, 90A, 123-136.

Hayase, H., T. Satake, I. Nishiyama and N. Ito 1969: Male sterility caused by cooling treatment at the meiotic stage in rice plants. II. The most sensitive stage to cooling and the fertilizing ability of pistils. Proceedings of the Crop Science Society of Japan, 38, 706-711.

Hayashi, Y., Y. Ishigooka M. Yokozawa, H. Toritani and S. Goto 2001: Impact of global warming on the potential characteristics of Japanese paddy rice cultivation, Global Environment, 6, 141-148 (in Japanese).

Horie, T. and H. Nakagawa 1990: Modelling and prediction of developmental process in rice. Japanese Journal of Crop Science, 59, 687-695 (in Japanese with English abstract).

Horie, T., H. Nakagawa, M. Ohnishi and J. Nakano 1995: Rice production in Japan under current and future climates. In Modeling the impact of climate change on rice production in Asia. eds. by Matthews R. B., M. J. Kropff, D. Bachelet and H. H. van Laar, CAB International, Oxon, pp. 143-164.

Iizumi, T., Y. Hayashi and F. Kimura 2007: Influence on rice production in Japan from cool and hot summers after global warming. Journal of Agricultural Meteorology, 63, 11-23.

Iizumi, T., M. Nishimori, Y. Ishigooka and M. Yokozawa 2010: Introduction to climate change scenario derived by statistical downscaling. Journal of Agricultural Meteorology, 66, 131-143 (in Japanese with English abstract).

Iizumi, T., M. Yokozawa and M. Nishimori 2011: Probabilistic evaluation of climate change impacts on paddy rice productivity in Japan. Climatic Change, 107, 391-415.

Kanda, E., Y. Torigoe and T. Kobayashi 2002: A simple model to predict the developmental stages of rice panicles using the effective accumulative temperature. Japanese Journal of Crop Science, 71, 394402 (in Japanese with English abstract).

Kanno, H. 1997: Classification of the Yamase (cold northeasterly wind around northeastern Japan) based upon its air-mass vertical structures. Journal of the Meteorological Society of Japan, 75, 10531071.

Kanno, H. 2004: Five-year cycle of north-south pressure difference as an index of summer weather in northern japan from 1982 onwards. Journal of the Meteorological Society of Japan, 82, 711-724.

Kanno, H., M. Watanabe and E. Kanda 2013: MIROC5 predictions of Yamase (cold northeasterly winds causing cool summers in northern Japan). Journal of Agricultural Meteorology, 69, 117-125.

Kudoh, T. 1984: Characteristics of Okhotsk air mass during the typical Yamase period (1981.6.18-21). Tenki, 31, 411-419 (in Japanese).

MAFF, 2013a: Paddy and Upland Rice Crop Area and Harvest Volume. Ministry of Agriculture, Forestry 
and Fisheries, Tokyo, http://www.maff.go.jp/e/tokei/ kikaku/nenji_e/87nenji/other/n163_164.xls.

MAFF, 2013b: Paddy and upland rice yield index and harvest Volume. Ministry of Agriculture, Forestry and Fisheries, Tokyo, http://www.e-stat.go.jp/SG1/ estat/Pdfdl.do?sinfid=000023621698 (in Japanese).

Mizuta, R., H. Yoshimura, H. Murakami, M. Matsueda, H. Endo, T. Ose, K. Kamiguchi, H. Hosaka, M., Sugi, S. Yukimoto, S. Kusunoki and A. Kitoh 2012: Climate simulations using MRI-AGCM3.2 with 20$\mathrm{km}$ grid. Journal of the Meteorological Society of Japan, 90A, 233-258.

Okada, M., H. Shimono, Y. Yamakawa, M. Inoue and K. Kobayashi 2005: Effects of elevated $\mathrm{CO}_{2}$ on floral sterility of rice plants caused by low temperature. Journal of Agricultural Meteorology, 60, 589-592.

Satake, T. 1976: Determination of the most sensitive stage to sterile-type cool injury in rice plants. Research Bulletin of the Hokkaido National Agricultural Experiment Station, 113, 1-44.

Shimono, H. 2008: Impact of global warming on yield fluctuation in rice in the northern part of Japan. Japanese Journal of Crop Science, 14, 489-497.
Shimono, H., M. Okada, E. Kanda and I. Arakawa 2007: Low temperature-induced sterility in rice: Evidence for the effects of temperature before panicle initiation. Field Crops Research, 101, 221-231.

Shimono, H., M. Okada, Y. Yamakawa, H. Nakamura, K. Kobayashi and T. Hasegawa 2008: Rice yield enhancement by elevated $\mathrm{CO}_{2}$ is reduced in cool weather. Global Change. Biology, 14, 276-284.

Shimono, H. 2011: Earlier rice phenology as a result of climate change can increase the risk of cold damage during reproductive growth in northern Japan. Agriculture, Ecosystems and Environment, 144, 201-207.

Takezawa, K. 2007: General linear regression applied to non-parametric regression. In Non-parametric regression for everyone (tome 2). Yoshioka Shoten. Kyoto, pp. 331-367 (in Japanese).

Uchijima, T. 1976: Some aspects of the relation between low air temperature and sterile spikelets number in rice plants. Journal of Agricultural Meteorology, 31, 199-202 (in Japanese).

Yokozawa, M. 2003: Mesh climate change data for evaluating climate change impacts in Japan under gradually increasing atmospheric $\mathrm{CO}_{2}$ concentration. Journal of Agricultural Meteorology, 59, 117-130. 